\title{
PENERAPAN SISTEM PENGENDALIAN MANAJEMEN BERDASARKAN AJARAN NICCOLO MACHIAVELLI TERHADAP PENINGKATAN KUALITAS KINERJA KARYAWAN PADA PT.X
}

\author{
Christopher Christian Hutomo \\ Jurusan Akuntansi, Fakultas Bisnis dan Ekonomika \\ cc.hutomo@gmail.com
}

\begin{abstract}
Abstrak - Sumber daya manusia merupakan unsur terpenting dalam menentukan kesuksesan atau kegagalan dalam implementasi strategi perusahaan. Sistem Pengendalian Manajemen membantu perusahaan dalam mengembangkan dan mengelola tindakan dari karyawannya sehingga perusahaan dapat mencapai tujuan yang ingin dicapainya. Penelitian ini menggunakan metode applied research. Dalam penelitian ini, peneliti terlebih dahulu akan melihat Sistem Pengendalian Manajemen yang telah diterapkan pada objek penelitian, yaitu PT.X. Dari hasil penelitian yang dilakukan peneliti menemukan masalah-masalah yang terjadi pada PT.X dan menganalisa sebesar apa dampak yang timbul dari masalah-masalah yang terjadi pada PT.X. Peneliti beranggapan bahwa masalah-masalah pada PT.X sejatinya banyak terjadi akibat dari kesalahan aspek manusianya. Maka dari itu, penelitian ini bertujuan membantu memberikan solusi terhadap masalah yang terjadi pada PT.X. Dalam hal ini, peneliti menggunakan ajaran Niccolo Machiavelli seorang sekretaris negara dari Florence, Italia yang begitu disegani di Eropa pada jaman Renaisans. Penelitian ini diharapkan dapat memberikan alternatif lain serta dukungan terhadap teori Sistem Pengendalian Manajemen yang telah ada dan diterapkan pada PT.X. Hasil dari penelitian ini akan memberikan rekomendasi kepada PT.X dalam menyelesaikan masalah-masalah yang terjadi pada PT.X
\end{abstract}

Kata kunci: Sistem Pengendalian Manajemen, Niccolo Machiavelli, The Prince.

Abstract - Human resources is the most important element in determining the
success or failure in the implementation of corporate strategy. Management
Control System helps companies in developing and managing the actions of its
employees so that the company can achieve the goals wherein the company want
to accomplish. This study uses applied research method. In this study, researcher
will first see Management Control System that has been applied to the object of
study, namely PT.X. From the results of the study conducted, researcher
discovered the problems that occur in PT.X and analyzes of what the effects of the
problems that occur in PT.X. Researcher assume that the problems in PT.X
actually occur due to many aspects of human error. Therefore, this study aims to
help provide solutions to the problems that occur in PT.X. In this case, researcher
used the teachings of Niccolo Machiavelli, a secretary of state of Florence, Italy is
so well respected in Europe in the Renaissance. This study is expected to provide
another alternative as well as support for the theory of MCS that already exist and
apply in PT.X. Results from this study will provide recommendations to PT.X in
resolving the problems that occur in PT.X. Keywords: Management Control Systems, Niccolo Machiavelli, The Prince. 


\section{PENDAHULUAN}

Sumber daya manusia merupakan unsur terpenting yang menentukan kesuksesan atau kegagalan implementasi strategi perusahaan karena manusia memegang peran seluruh aspek strategis dan operasional perusahaan. Sebaik apapun sistem yang dibangun, jika aspek manusia tidak mendapat perhatian cukup, maka akan menciptakan kekacauan(Soeherman, 2015). Peran sistem pengendalian manajemen dalam perubahan organisasi telah menjadi perhatian penting bagi praktisi dan penelitian di bidang akuntansi manajemen (Burns \& Vaivio, 2001). Dalam dunia pembelajaran sistem pengendalian manajemen, banyak orang yang telah mengetahui tentang peranan kitab perang Sun Tzu dalam peningkatan efektifitas sistem pengendalian manajemen dalam suatu perusahaan. Sun Tzu sendiri merupakan seorang filsuf yang hebat yang berasal dari negeri Tiongkok yang notabene menggunakan budaya timur, disini peneliti melihat sosok menarik lainnya dari Niccolo Machiavelli, filsuf negeri Italia yang notabene menggunakan budaya barat, Niccolo Machiaveli mengajarkan dua ajaran penting mengenai konsep virtú dan fortuna.

Dalam kaitannya dengan penerapan ajaran Niccolo Machiavelli dalam bidang SPM, Gerrard A. Callanan (2004) berpendapat bahwa penggunaan taktik untuk menimbulkan rasa takut, penimbunan kekuasaan dan informasi dan penggunaan kebijakan dan aturan formal yang dapat membatasi tindakan yang dapat dilakukan oleh lo-level management harus diganti dengan sebuah filosofi pemberdayaan yang mendorong kerja sama tim, partisipasi dan kontribusi. Penelitian ini menyatakan bahwa pada abad ke-21, adalah saat untuk meninggalkan filosofi dari Machiavelli dan menyatakan bahwa untuk kepemimpinan jaman sekarang "lebih aman untuk dicintai daripada ditakuti".

Namun bila peneliti menganalisa lebih dalam dari penelitian oleh Simon Moore (2012) menyatakan bahwa Machiavelli menggunakan komunikasi untuk membangun reputasi popular dan kuat di mata publik, untuk "mengubah the vinegar of violence menjadi the wine of civic harmony" (Ball, 1984, hal. 533). Peneliti telah menemukan sosok yang sangat Machiavelli dari Hillary Devey dalam BBC Documentary(2013), beliau adalah pemilik Pall-Ex, perusahaan freight forwarding asal Inggris. Di dalam film tersebut Hilary Devey menyatakan 
bahwa dirinya adalah sosok yang sangat setuju dengan penerapan ajaran Machiavelli, dirinya juga menyebutkan bahwa para kompetitornya dalam Dragon's Den masing-masing merupakan contoh orang-orang dengan topeng Machiavelli, maka dari itu dia harus berpikir keras untuk mengetahui strategi apakah yang dipakai oleh para kompetitornya.

Menurut Farneworth (1815), Hanya sedikit orang yang memiliki sifat dasar pemberani, tetapi disiplin yang baik dan pengalaman membuat banyak orang menjadi pemberani dan dalam bukunya juga dibahas bahwa tata tertib yang baik serta disiplin dalam sebuah pasukan lebih bisa diandalkan ketimbang kekuatan dan kebuasan. Disini peneliti menangkap makna bahwa Machiavelli sadar akan sedikitnya orang-orang yang bertalenta dan dengan disiplin dan pengalaman dapat melatih orang-orang biasa menjadi kompeten dan bahwa seorang bawahan yang memiliki disiplin tinggi lebih berharga daripada seseorang yang bertalenta namun tidak disiplin dalam bekerja. Ajaran dari Machiavelli ini seringkali terlihat pada perusahaan perbankan, karena biasanya perusahaan perbankan memiliki disiplin yang tinggi kepada para bawahannya baik dalam hal peraturan maupun target.

Selain itu buku Machiavelli The Prince adalah buku yang mengajarkan tentang bagaimana mendapatkan power dan memperthankannya. Hal inilah yang penting bagi top management dalam mempertahankan prinsip going concern perusahaan. Menurut Michael Dobbs penulis House of Cards dalam BBC Documentary (2013), inti dalam buku Machiavelli adalah jika seseorang menjadi seorang terhebat di dunia. Tetapi bila orang tersebut belum mempunyai power dan belum tahu cara menggunakannya. Orang tersebut hanya membuang waktunya. Hal ini sama dengan seseorang manajer yang sebenarnya memiliki peran untuk melakukan pengendalian terhadap suatu perusahaan, dimana manajer disini harus mengerti bagaimana dirinya dapat mengendalikan bawahan-bawahannya.

Hal penting lainnya yang dapat diperoleh dari konsep yang diajarkan oleh Machiavelli adalah bahwa seseorang yang duduk pada posisi top management hendaknya bukanlah orang-orang yang baik, melainkan orang-orang yang mampu. George R.R. Martin penulis Game of Thrones, berkata: “Apabila ada seseorang yang baik, bukan berarti dia bisa menjadi seorang pemimpin yang baik di dunia 
ini. Tidak cukup hanya dengan mengatakan aku akan menjadi baik, aku akan menjadi bijak, aku akan melakukan hal yang benar. Pertanyaannya adalah apa itu hal yang benar?" Menurut Google dalam BBC Documentary (2013), Dont be evil (motto google) adalah hal yang benar. Tetapi bila dilihat lebih dalam lagi, mungkin masyarakat memandang Google, Facebook atau Apple perusahaan digital terbesar di dunia tampak baik di luar karena perusahaan-perusahaan tersebut memang harus menjaga reputasi mereka, tetapi pastilah sebenarnya mereka tidak sebaik itu dibelakang. Hal ini didukung oleh pernyataan dari Robert Green dalam BBC Documentary (2013), menurutnya Machiavelli adalah orang pertama yang menganalisa pentingnya penampilan (appereance) yang dimiliki seseorang. Seseorang dapat menjadi seseorang yang buruk, tetapi dia harus tetap memiliki reputasi yang baik. Demikian pula dengan top management sebaiknya mereka bukanlah orang-orang yang baik tetapi orang-orang yang mampu menyelesaikan pekerjaan mereka dengan baik tetapi tetap menjaga reputasinya sebagai orang yang baik.

Tujuan dari penelitian ini adalah explanatory research karena penelitian ini bertujuan untuk menjelaskan manfaat dari implementasi ajaran Niccolo Machiavelli terhadap pengendalian manajemen dalam pada PT.X. Peneliti ingin membuktikan bahwa dalam dunia ini, ternyata ada ajaran lain yang ternyata dapat digunakan juga dalam pengembangan sistem pengendalian manajemen dalam suatu perusahaan bahkan ajaran ini telah dibaca oleh Napoleon Bonaparte dan Frederick Yang Agung, maka dari itu peneliti mengangkat topik "Penerapan Sistem Pengendalian Manajemen Berdasarkan Ajaran Niccolo Machiavelli Terhadap Peningkatan Kualitas Kinerja Karyawan pada PT.X” dalam penelitian ini.

\section{METODE PENELITIAN}

Dalam melakukan penelitian terkait peneliti menggunakan beberapa metode penelitian untuk menjawab research question yang ada yang nantinya bertujuan untuk menemukan konsep dari ajaran Niccolo Machiavelli yang dapat dipakai dalam menyelesaikan masalah-masalah pada PT.X dan meningkatkan kualitas kinerja karyawan pada PT.X. 
Yang pertama, untuk mengetahui sistem pengendalian yang telah ada dalam PT.X, masalah-masalah yang ada serta dampak yang disebabkan, peneliti memperoleh sumber data dari interview dan observasi. Interview ditujukan kepada Bapak X sebagai pemilik untuk mengetahui bagaimana penerapan sistem pengendalian manajemen selama ini, serta peneliti akan meng-interview kepala produksi untuk mengetahui seperti apakah SPM yang telah mereka jalani selama ini pada bagian produksi

Interview menggunakan semi-terstruktur dan tidak terstruktur yang bertujuan agar peneliti dapat menggali lebih dalam atas hasil dari interview dengan berbagai pihak yang terlibat, dengan alokasi waktu kurang lebih 15-30 menit tiap pertemuan untuk tiap orang. Interview dengan Bapak X dilakukan lebih dari 5 kali, selain itu 1 kali. Peneliti menggunakan media perekam suara, dan laptop

Selain itu peneliti juga melakukan observasi dengan metode observasi non participant observation, untuk menyesuaikan hasil interview dengan kenyataan yang ada, observasi dilakukan kurang lebih 4 jam seminggu dan dimulai pada tanggal 1 September 2015.

Dari observasi dan interview yang telah peneliti lakukan, ditemukan sistem pengendalian manajemen yang dipakai oleh perusahaan, yang kemudian oleh peneliti dirangkum sesuai dengan SPM Modern milik Merchant dan Van der Stede. Dari situlah akhirnya peneliti membagi SPM perusahaan kedalam 4 jenis pengendalian yaitu: action control, result control, personnel control, dan cultural control.

Yang kedua, untuk mendapatkan konsep SPM dari ajaran Niccolo Machiavelli peneliti mendapatkan data melalui analisis dokumen baik melihat video, membaca dari jurnal-jurnal, serta membaca buku karya Niccolo Machiavelli seperti The Art of War yang telah diterjemahkan ke bahasa Indonesia, The Prince buku pertama Niccolo Machiavelli, dan The Discources buku kedua Niccolo Machiavelli.

Banyak sekali ajaran penting yang didapat dari pemahaman seorang Niccolo Machiavelli,yaitu: 
1. Mencapai Tujuan Adalah yang Terpenting

2. Belajar dari Pengalaman

3. Punishment and Reward

4. Adaptif dan Selektif

5. Efektifitas dan Efisiensi

6. Pembuatan dan Pelaksanaan Peraturan

7. Delectus

8. Mengenali Trouble Maker

9. Memperlakukan Karyawan dengan Baik

10. Fortuna

Yang nantinya dapat diinterpretasikan secara kreatif menjadi pelengkap dalam ilmu sistem pengendalian manajemen yang dapat digunakan oleh perusahaan-perusahaan manapun. Dari SPM yang terbentuk dari ajaran Niccolo Machiavelli ini, tentunya peneliti berharap dapat menyelesaikan masalah-masalah SPM yang terjadi pada bagian produksi dalam PT.X

\section{HASIL DAN PEMBAHASAN}

Melalui beberapa sumber yang berasal dari artikel, buku, jurnal, maupun video yang didapat oleh peneliti, maka peneliti akhirnya dapat merumuskan dan merangkum beberapa ajaran moral penting yang dapat dipetik dari ajaran Niccolo Machiavelli. Nilai-nilai yang didapat dari buku karya Niccolo Machiavelli ini diharapkan dapat memberikan manfaat pada dunia akuntansi, seperti bagaimana sebelumnya buku karyanya dapat memberikan dampak yang begitu besar pada bidang politik di seluruh dunia. Perlu diketahui bahwa The Prince buku karya Niccolo Machiavelli yang pertama adalah buku yang sangat diagungkan di seluruh dunia, bahkan buku karyanya termasuk dalam 3 buku paling terkenal di seantero Italia, khususnya di Florence tempat tinggalnya, dan bersaing dengan 2 buku lainnya seperti Pinnocio dan Dante. Dalam ajarannya Machiavelli menggarisbawahi dua hal penting yaitu mengenai Virtú dan Fortuna. Virtú menurut Budac(2015), adalah kualitas personal yang dibutuhkan oleh seorang raja untuk mengelola negaranya dan meningkatkan kekuasaannya. Untuk dapat menjadi seseorang yang memiliki kualitas virtú, raja harus bersifat fleksibel 
(flexible disposition). Sikap ini maksudnya adalah sikap untuk dapat adaptif dengan perubahan lingkungan yang ada. Tetapi dalam bukunya The Prince, Machiavelli (2001) juga berkata, “It cannot be called virtú to kill one's fellow citizens, betray one's friends, be without faith, without pity, and without religion; by these methods one may indeed gain power, but not glory." Sedangkan fortuna berasal dari sesuatu yang tidak dapat dikendalikan oleh manusia yang bersifat keberuntungan. Perlu diketahui, bahwa Machiavelli bukanlah seseorang yang menanamkan sifat ketakutan yang wajib diterapkan pimpinan pada bawahannya tetapi lebih ke seseorang dengan sifat skeptis untuk mencegah hal-hal yang buruk terjadi. Berikut adalah beberapa ajaran moral penting Niccolo Machiavelli yang menurut peneliti dapat berguna bagi dunia akuntansi khususnya pada bidang SPM:

\section{Mencapai Tujuan Adalah yang Terpenting}

\section{"The Ends Justify The Means"}

Banyak yang berpikir bahwa apa yang diajarkan Machiavelli adalah sesuatu yang kejam bahkan gereja Katolik pernah melarang beredarnya ajaran ini selama beberapa tahun. Machiavelli juga ternyata dikenal sebagai seorang yang antiChris, tetapi disisi lain dia adalah seorang realist yang pandai. Sesuai dengan apa yang dikatakan oleh Kolonel Tim Collins, mantan perwira Inggris, dalam $B B C$ Documentary (2013), menurutnya Machiavelli adalah seorang yang baik karena dia mendeskripsikan dengan baik apa yang dilihatnya dan dia menuliskannya secara sangat akurat sehingga berguna untuk siapapun yang membacanya bahkan setelah berabad-abad kemudian. Pelajaran Niccolo Machiavelli yang didapat dari kata-kata "The Ends Justify The Means" bahwa sebenarnya dalam perusahaan mencapai tujuan adalah segala-galanya dan karena pentingnya hal tersebut tujuan ini boleh diraih dengan cara apapun. Maka dari itu, dalam perusahaan pun perlu adanya pemikiran yang realistis untuk dapat mencapai tujuan perusahaan, dan ini berlaku dalam berbagai hal, yaitu:

- $\quad$ Target

Pembuatan target yang dibuat oleh perusahaan baik itu adalah jangka panjang, maupun jangka pendek. Target mingguan, bulanan, tahunan, maupun 
jangka panjang hendaknya dibuat sesuai dengan kapasitas produksi dan jumlah tenaga kerja yang realistis. Perhitungan ini harus sangat mendetail sehingga target yang dibuat dapat dijalankan secara efektif. Dalam bukunya, Machiavelli(1557), berkata "the quickest way of opening the eyes of the people is to find the means of making them descend to particulars, seeing that to look at things only in a general way deceives them." Dalam pembuatan target penting juga untuk membuat target yang dapat terukur. Pembuatan target yang teukur berawal dari pembuatan tujuan jangka panjang yang kemudian dipecah lagi kedalam tindakan-tindakan jangka pendek yang dapat terukur. Karena manusia cenderung tidak mengerti tujuan yang dibuat secara umum dan lebih paham tujuan yang telah disederhanakan dalam bentuk langkah-langkah jangka pendek yang lebih spesifik.

\section{Training}

Dengan tidak adanya pelatihan yang mumpuni tentu saja tidak didapat karyawan/ tenaga kerja yang memiliki kualitas kerja yang handal. Maka dari itu perlu adanya sikap realistis dari top management, maupun bawahannya untuk mau mengadakan/ menjalani pelatihan untuk meningkatkan kualitas diri sehingga tujuan perusahaan dapat tercapai. Dalam buku Machiavelli karya Farneworth (1815), The Art of War dijelaskan bahwa dahulu bangsa Romawi melatih pasukannya yang hendak berperang dengan pakaian besi dan pedang yang lebih berat sehingga pada saat berperang dengan baju besi dan pedang yang lebih ringan pergerakan mereka menjadi lebih cepat dan tangkas.

\section{Belajar dari Pengalaman}

"Wise men say, and not without reason, that whoever wishes to foresee the future must consult the past; for human events ever resemble those of preceding times. “

Mungkin seringkali kita dengar kata-kata, "experience is the best teacher." Pengalaman yang tentunya seseorang dapatkan dari masa lalunya ataupun masa lalu orang lain adalah hal yang penting untuk menjadi bekal seseorang kedepan. Karena dengan mengalami kegagalan seseorang dapat mendapatkan suatu pelajaran yang tidak didapatinya ketika dia mendapatkan keberhasilan secara 
instan. Dengan melakukan kesalahan maka seseorang belajar apa yang benar dan salah, apa yang seharusnya dilakukan dan tidak dilakukan. Maka dari itu, dalam suatu perusahaan perlu ditanamkan suatu pemikiran untuk belajar dari pengalaman yang ada. Hal ini dapat berlaku dalam pembuatan anggaran pada tahun kedepan, dalam pembuatan aturan yang berlaku di perusahaan, dalam menerapkan pelatihan, dalam pengambilan keputusan, dan dalam banyak hal lainnya.

\section{Punishment and Reward}

Dalam mencapai target perusahaan walaupun kapasitas produksi telah mumpuni tetapi sangat diperlukan karyawan yang termotivasi dengan baik untuk mencapai target tersebut. Hal ini penting karena sikap dasar manusia yang terdiri dari 2 sikap yiatu gain pleasure dan avoid pain.

Pemberian reward and punishment akan sangat berguna dalam memacu karyawan untuk mencapai target perusahaan. Hukuman dapat membatasi perilaku yang tidak diinginkan untuk terjadi dan lebih bersifat mendidik. Hal ini sesuai dengan ajaran Machiavelli yang mengatakan "is much safer to be feared than loved", karena baginya love terkait dengan hubungan dengan kewajiban/ hutang,

yang karena kenaifan seseorang dapat merusak koneksi ini dalam suatu kesempatan untuk keuntungannya secara pribadi. Tetapi fear dapat diandalkan karena orang akan takut pada hukuman yang dapat terjadi padanya yang tidak pernah gagal.

Tetapi bukan berarti penghargaan tidaklah penting bagi karyawan suatu perusahaan. Menurut bukunya yang lain The Dircources (1998), Machiavelli berkata bahwa "Men cannot be made to bear labor and privations without the inducement of a corresponding reward, nor can they be deprived of such hope of reward without danger." penghargaan dapat berfungsi sebagai motivasi untuk memacu karyawan agar dapat mencapai prestasi dan memberikan petunjuk bagi seseorang yang memiliki kemampuan lebih.

\section{Adaptif dan Selektif}

“One change always leaves the way prepared for the introduction of another." 
Machiavelli menyadari bahwa pada setiap jaman pasti ada perubahan yang terjadi, dan Machiavelli dalam bukunya The Prince (2001), mengatakan bahwa penting bagi pangeran yang baru mendapatkan warisan untuk menguasai kerjaaan dari seorang raja untuk dapat menghadapi perubahan jaman yang terus berkembang dengan hati-hati. Hal terpenting yang perlu diingat sesuai dengan ajaran Machiavelli disni bahwa satu perubahan akan selalu memiliki dampak pada terjadinya perubahan yang lain. Maka dari itu perlu adanya sikap prudent(hati-hati) dalam menyikapi perubahan jaman yang ada. Machiavelli (1998), dalam bukunya The Discourses mengatakan, "the causes of the success or failure of men depend upon their manner of suiting their conduct to the times." Artinya penyebab dari suatu kesuksesan atau kegagalan sebenarnya tergantung dari bagaimana sikap seseorang dalam mengatasi perubahan jaman. Seperti dalam perusahaan, seorang pemimpin harus peka terhadap kreatifitas karyawannya yang mungkin dapat menemukan cara yang lebih efektif dan efisien dalam menghadapi masalah dan menerapkannya, tetapi pelu diingat bahwa tidak setiap perubahan mengarah ke sesuatu yang baik, maka dari itu perlu adanya sikap selektif dari top management untuk menyikapi perubahan yang ada.

\section{Efektifitas dan Efisiensi}

\section{"How to be Able Not to be Good"}

Seringkali orang selalu bertanya, apakah tindakan yang benar itu selalu baik? Dan apakah tindakan yang baik selalu benar? Menurut peneliti, sebenarnya masyarakat sudah sadar bahwa tindakan yang baik belum tentu benar dan jika kita mau melakukan yang benar maka itu juga belum tentu baik. Machiavelli pun beranggapan demikian, hasil karyanya ini adalah sesuatu yang tidak bisa dihindarkan dari kenyataan yang ada. Artinya disini sebagai seorang pemimpin sebaiknya tidak membatasi kreatifitas yang mungkin dimiliki oleh bawahannya. Terkadang tidaklah baik untuk membatasi pekerjaan apa saja yang dapat dilakukan oleh karyawannya dan menentukan mana yang boleh dilakukan atau tidak tanpa melihat pandangan karyawan yang bersangkutan. Hal ini dikarenakan manusia adalah makhluk yang sangat kreatif, apabila karyawan tersebut dapat 
melakukan pekerjaannya dengan lebih efektif dan efisien maka sebaiknya cara dari bawahan tadi dalam menyelesaikan tugasnya dapat menjadi panutan bagi karyawan lainnya, bukan malah dilarang. Selain itu manajer perlu untuk bertindak efektif dan efisien juga dalam melakukan tugasnya sesuai dengan yang tertulis pada The Prince, Machiavelli (1537), "never attempt to win by force what can be won by deception." Hal ini berlaku dalam memotivasi bawahannya agar dapat bekerja secara efektif dan efisien, karena force lebih bersifat memaksa dan hal ini terkadang akan menimbulkan motivational problem dalam pelaksanaanya, sedangkan deception adalah suatu muslihat / pendayaan yang mirip dengan cara doktrinasi. Sehingga bawahan menemukan suatu tujuan yang harus diselesaikannya untuk memenuhi tujuannya dan juga tujuan perusahaan.

\section{Pembuatan dan Pelaksanaan Peraturan}

"Those who lay the foundations of a state and give it laws must assume that all men are bad and will always show their evil nature when they are given a chance."

Menurut Kamus Besar Bahasa Indonesia (2015), peraturan adalah tataan, petunjuk, kaidah, ketentuan yang dibuat untuk mengatur. Dalam membuat suatu peraturan agar bisa menjadi petunjuk yang baik untuk mengatur karyawannya terlebih dahulu seorang pemilik harus bersikap skeptis dan menganggap semua manusia adalah makhluk yang jahat dan akan menunjukan sisi buruknya ketika diberikan kesempatan. Dalam bukunya The Discources, Machiavelli (1998) berkata:" I think that there can be no worse example in a republic than to make a law and not to observe it; the more so when it is disregarded by the very parties who make it." Jadi top management sebagai bagian yang paling berperan dalam membuat peraturan harus juga mengawasi jalannya peraturan yang ada serta menaati peraturan yang dibuatnya, karena bila top management dapat menaati peraturan yang dibuatnya maka ini akan dijadikan panutan bagi bawahannya untuk menaati peraturan yang ada ataupun sebaliknya. Pembuatan peraturan ini tetapi bukan dimaksudkan untuk melarang atau membatasi kreativitas karyawan tetapi lebih kepada melarang sesuatu yang benar-benar merugikan perusahaan dan membahayakan lingkungan perusahaan. 


\section{Delectus}

"The first method for estimating the intelligence of a ruler is to look at the men he has around him."

Menurut buku The Art of War karya Farneworth (1815), delectus berasal dari kata latin deligo yang artinya memilih; memilah-milah. Konteks ini diperhatikan oleh Machiavelli terutama dalam hal calon perwira dan analog dengan Selective Service System (Sistem Penugasan yang Selektif). Dalam buku The Artof War, sistem delectus ini digunakan untuk memilih angkatan perang, tetapi peneliti beranggapan bahwa hal ini dapat diterapkan juga pada suatu perusahaan. Dalam suatu perusahaan pun sangat penting untuk diadakan suatu bentuk seleksi terhadap karyawan yang mau masuk dalam lingkungan perusahaan karena seleksi yang efektif dapat menghasilkan pelatihan yang efektif pula sehingga berujung pada tindakan yang efektif. Karena dari itu, delectus termasuk dalam langkah awal untuk memperoleh karyawan yang dapat bertindak secara efektif.

\section{Mengenali Trouble Maker}

"There are two methods of fighting, the one by the law, the other by force: the first method is that of men, the second of beasts; but as the first method is often insufficient, one must have recourse to the second."

Terkadang dalam suatu perusahaan, akan dapat dijumpai karyawan yang malas, curang, kurang disiplin, suka menipu, pemarah, dan beberapa tipe lainnya. Tetapi kebanyakan dari tipe-tipe jelek ini akan dapat diatasi oleh pemberian motivasi dan pelatihan serta dapat juga dibatasi oleh peraturan. Tetapi ternyata dalam dunia ini terdapat tipe karyawan yang entah karena masa lalunya ataupun apapun yang terjadi pada hidupnya sebelumnya yang memungkinkan orang tersebut tidak dapat dikendalikan atau selalu membangkang. Dalam bukunya The Prince, Machiavelli(2001) berkata juga,"There are three different kinds of brains, the one understands things unassisted, the other understands things when shown by others, the third understands neither alone nor with the explanation of others. The first kind is most excellent, the second also excellent, but the third useless." Seorang manajer harus dapat mengenali beberapa tipe karyawan ini, dalam mengatasi karyawan seperti ini manajer harus bertindak sangat tegas dan bila perlu 
melakukan keputusan akhir seperti perumahan karyawan jika diperlukan dengan melihat juga pada peraturan pemerintahan yang ada.

\section{Memperlakukan Karyawan dengan Baik}

\section{"When men are well governed, they neither seek nor desire any other liberty."}

Mungkin Google adalah contoh terbaik dari perusahaan yang menerapkan prinsip ini. Mudahnya bila perusahaan ingin seseorang bekerja secara maksimal penuhilah dulu kebutuhannya. Kemudahan tersebut dapat berupa fasilitas seperti alat kerja yang layak, lingkungan yang tertata dengan baik, maupun dari segi gaji yang diberikan. Seperti karyawan Google yang menemukan alasan kuat kenapa dirinya harus bekerja dengan giat karena kebutuhannya sudah dipenuhi perusahaan, seperti itulah harusnya perusahaan-perusahaan di Indonesia memperlakukan karyawannya. Dalam bukunya The Prince, Machiavelli(2001) juga berkata, "Nor can there be great difficulty where there is great willingness." Tidak ada sesuatu yang benar-benar sulit apabila terdapat kemauan yang besar, dan kemauan yang besar berasal dari telah terpenuhinya kebutuhan individu karyawan sebagai manusia.

\section{Fortuna}

Fortuna seringkali diartikan seperti fortune dalam bahasa Inggris ataupun keberuntungan dalam bahasa Indonesia. Seringkali seseorang sudah berusaha amat keras dan sangat sulit mencapai apa yang diinginkannya sedangkan orang lain dengan mudah mencapainya, inilah pengaruh dari Fortuna. Setiap perusahaan perlu untuk tetap mengembangkan virtú-nya masing-masing karena tidak ada yang mengetahui kapan fortuna akan menghampiri. Fortuna juga berhubungan dengan systematic dan unsystematic risk, dimana Fortuna masuk ke dalam golongan unsystematic risk, yang merupakan sesuatu yang tidak dapat dipastikan kapan akan terjadi dan tidak dapat dikendalikan oleh perusahaan. 


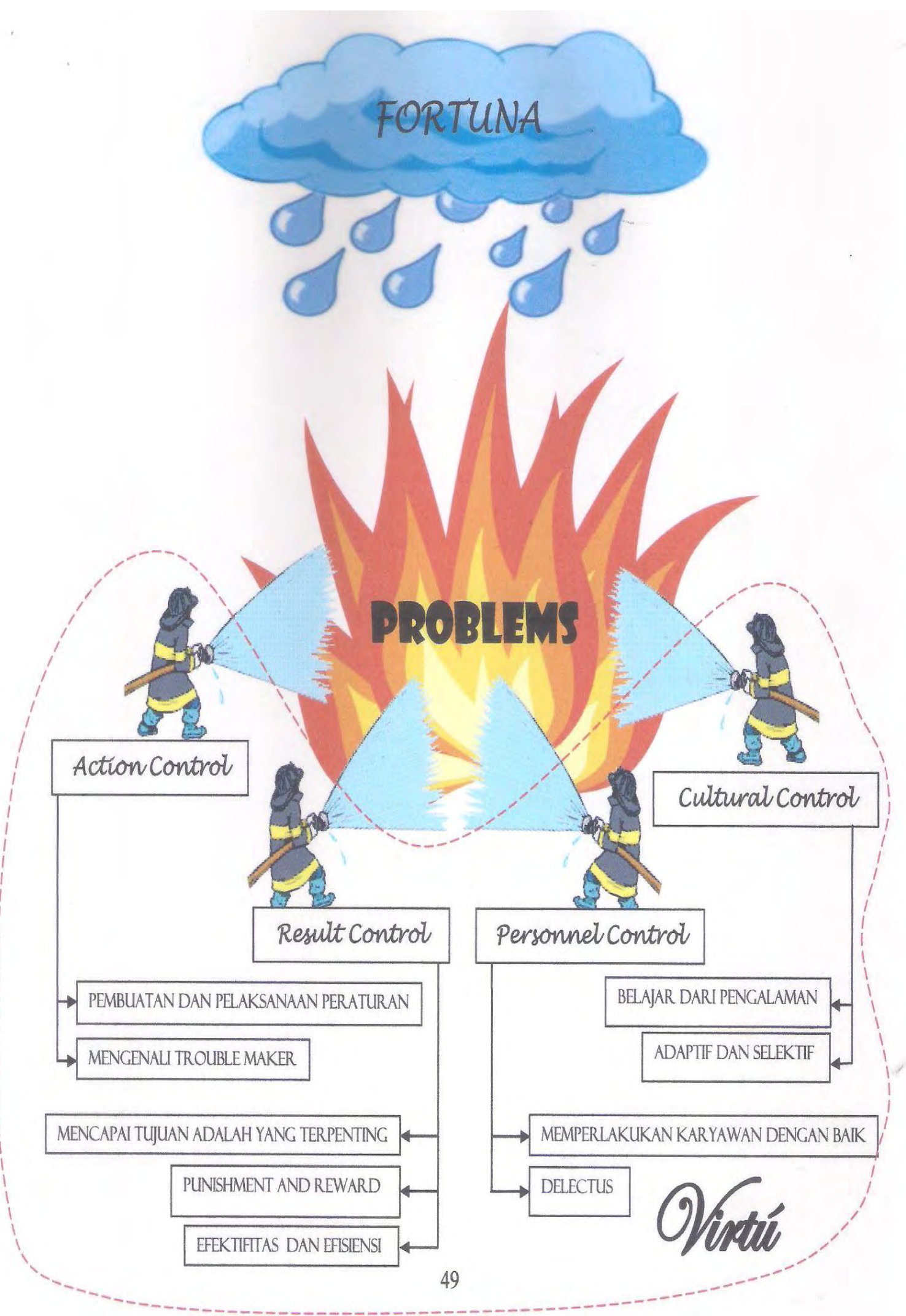

Gambar 2.1

Model Konseptual Niccolo Machiavelli

(sumber: olahan peneliti) 
Setiap perusahaan pasti hendak berkembang kearah yang lebih baik, maka dari itu perlu dilakukan penanggulangan terhadap masalah-masalah yang ada. Khususnya pada masalah yang memiliki dampak yang begitu signifikan seperti masalah-masalah yang ada pada PT.X. Dengan latar belakang demikian, peneliti mengangkat ajaran Niccolo Machiavelli untuk bisa menjadi penyelamat daripada PT.X dalam memberantas masalah-masalah yang dihadapinya, sehingga pekerjaan yang dilakukan dapat menjadi lebih efektif dan agar PT.X dapat memiliki orientasi ke depan yang lebih baik.

Ajaran Machiavelli menekankan tentang pentingnya untuk menjadi seseorang yang dapat berpikir secara adaptif dan selektif terhadap perubahan jaman dengan didasari dengan virtú yang menekankan bagaimana manajemen dapat mengendalikan bawahannya dengan sikap flexible disposition yang mengajarkan tentang watak yang fleksibel dalam mengatasi dinamika masalah yang terjadi di perusahaan serta dalam menghadapi perkembangan jaman. Dalam mengimplementasikan ajaran Niccolo Machiavelli sebagai suatu konsep SPM yang baru, perlu juga memperhatikan peraturan-peraturan pemerintahan yang berlaku terutama UU 13 no 2013 yang mengatur tentang ketenagakerjaan. 
Tabel 1

Masalah yang Terjadi pada PT.X dan Rekomendasi Menurut Ajaran Niccolo Machiavelli

\begin{tabular}{|c|c|c|c|}
\hline & Masalah yang terjadi & Filosofi Machiavelli & Rekomendasi untuk pembenahan masalah \\
\hline 1 & 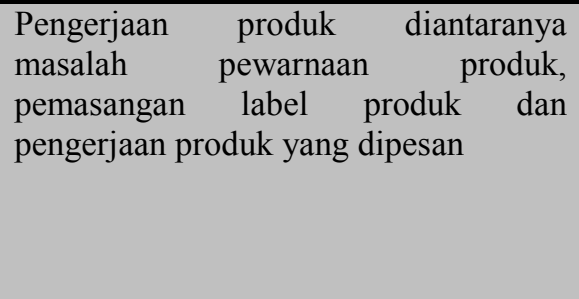 & $\begin{array}{l}\text { "Mencapai Tujuan Adalah yang terpenting" } \\
\text { "Belajar dari Pengalaman" }\end{array}$ & $\begin{array}{l}\text { - Adanya training tidak hanya on the job } \\
\text { training tetapi juga off the job training yang } \\
\text { berguna untuk jangka panjang PT.X } \\
\text { - Adanya penilaian kinerja terhadap: } \\
\text { Kuantitas, kualitas, jangka waktu } \\
\text { pengerjaan, kehadiran di tempat, dan sikap } \\
\text { kooperatif }\end{array}$ \\
\hline 2 & $\begin{array}{l}\text { Karyawan yang tidak bekerja sesuai } \\
\text { dengan prosedur }\end{array}$ & $\begin{array}{l}\text { "Punishment and Reward” } \\
\text { "Mengenali Trouble Maker" }\end{array}$ & $\begin{array}{l}\text { - Karyawan yang terus menerus tidak } \\
\text { bersikapkooperatif dapat dirumahkan bila } \\
\text { sudah malampau batas kewajaran, hal ini } \\
\text { diharapkan juga dapat dijadikan contoh } \\
\text { punishment untuk karyawan yang lain. } \\
\text { Pertimbangankan juga UU no } 13 \text { tahun } \\
2013 \text { tentang ketenagakerjaan. } \\
\text { - Manajemen harus dapat melihat karyawan } \\
\text { manakah yang mampu tanpa pertolongan, } \\
\text { mampu dengan pertolongan atau karyawan } \\
\text { yang tidak mampu dengan sendiri maupun } \\
\text { dengan pertolongan. }\end{array}$ \\
\hline 3 & Hubungan kerja antar divisi & $\begin{array}{l}\text { "Belajar dari Pengalaman" } \\
\text { "Efektifitas dan Efisiensi" }\end{array}$ & $\begin{array}{l}\text { - Meningkatkan penilaian kinerja terhadap } \\
\text { bagian pemasaran PT.X agar salesnya dapat } \\
\text { segera mengerti demand dari pasar, dan } \\
\text { sales juga harus bersikap kooperatif } \\
\text { terhadap top management. }\end{array}$ \\
\hline 4 & $\begin{array}{l}\text { Kondisi ruangan yang tidak tertata } \\
\text { dengan baik }\end{array}$ & "Memperlakukan Karyawan dengan Baik" & $\begin{array}{l}\text { - Kondisi ruangan yang tidak baik ditakutkan } \\
\text { akan dapat berdampak terhadap motivasi } \\
\text { bekerja para karyawan, maka dari itu } \\
\text { rekomendasi yang disarankan oleh peneliti } \\
\text { adalah menumbuhkan kesadaran peneliti }\end{array}$ \\
\hline
\end{tabular}


Calyptra: Jurnal IImiah Mahasiswa Universitas Surabaya Vol.5 No.2 (2016)

\begin{tabular}{|c|c|c|c|}
\hline & & & $\begin{array}{l}\text { dengan kembali ke prinsip "Memperlakukar } \\
\text { Karyawan dengan Baik" }\end{array}$ \\
\hline 5 & Penagihan terhadap pelanggan & $\begin{array}{l}\text { "Adaptif dan Selektif" } \\
\text { "Delectus" }\end{array}$ & $\begin{array}{l}\text { - Melakukan proses yang selektif pada saa } \\
\text { menerima tawaran dari pelanggan sehingga } \\
\text { perusahaan tidak terancam kemacetan aru } \\
\text { kas karena banyaknya pelanggan yang suli } \\
\text { ditagih. } \\
\text { - Menetapkan credit limit }\end{array}$ \\
\hline 6 & $\begin{array}{l}\text { Kurangnya ketegasan dalam } \\
\text { menjalankan peraturan yang ada }\end{array}$ & $\begin{array}{c}\text { "Pembuatan dan Pelaksanaan Peraturan" } \\
\text { "Punishment and Reward" }\end{array}$ & $\begin{array}{l}\text { - Dengan melakukan pengawasan terhadar } \\
\text { peraturan yang ada seacara konsisten dar } \\
\text { juga penidakan yang tegas terhadap } \\
\text { karyawan yang melanggarnya. }\end{array}$ \\
\hline
\end{tabular}




\section{KESIMPULAN DAN SARAN}

Peneliti meyakini bahwa konsep SPM dengan ajaran Niccolo Machiavelli akan dapat membantu banyak perusahaan dalam mengatasi masalahnya seperti halnya dalam PT.X. tetapi disini dibutuhkan adanya tindakan yang kooperatif dari pihak manajemen untuk dapat menerapkan konsep ini secara konsisten sehingga dapat meningkatkan kualitas kinerja karyawan pada PT.X.

Sebelum penelitian ini dilakukan, peneliti sedikit sekali menemukan penelitian yang menghubungkan langsung ajaran Niccolo Machiavelli dengan Sistem Pengendalian Manajemen. Hal ini membuat peneliti mengalami beberapa kesulitan dalam mengambil intisari dari ajaran Niccolo Machiavelli yang dapat berguna untuk mendukung Sistem Pengendalian Manajemen yang ada pada perusahaan. Dengan telah dilakukannya penelitian ini, diharapkan penelitian berikutnya dapat mengupas lebih dalam mengenai ajaran Niccolo Machiavelli yang dapat berguna dalam mendukung Sistem Pengendalian Manajemen suatu perusahaan.

Pada penelitian berikutnya, peneliti juga berharap bahwa penelitian berikutnya dapat membahas keseluruhan masalah yang terdapat pada badan usaha, hal ini dikarenakan pada penelitian ini masalah yang dibahas lebih fokus hanya pada pada bagian produksi saja. Peneliti juga berharap bahwa untuk penelitian selanjutnya dapat digunakan lebih dari 1 badan usaha yang diteliti agar dapat digeneralisasikan dengan objek yang lain. 


\section{DAFTAR PUSTAKA}

Anthony, Robert N. and Vijay Govindarajan. 2007. Management Control Systems, $12^{\text {th }}$ edition. New York: McGraw - Hill.

Ball, Terence. 1984. The Picaresque Prince, Reflections on Machiavelli and Moral Change. Political Theory, Vol. 12 Iss: 4 pp. 521-536.

BBC Documentary. 2013. Who's Afraid Of Machiavelli. https://www.youtube.com/watch? $=$ sMkt1Vq7tJ4 (diunduh tanggal 15 Agustus 2015).

Budac, Christina. 2015. International Workshop on Ideologies, Values and Political Behaviors in Central and Eastern Europe. Procedia - Social and Behavioral Sciences, Vol.183 pp. 129-134.

Burns, John and Juhani Vaivio. 2001. Management Accounting Change. Management Accounting Research, Vol. 12 Iss: 4 pp. 389-402.

Callanan, Gerard A. 2004. What Would Machiavelli Think? An Overview of The Leadership Challenges in Team-Based Structures. Team Performance Management: An International Journal, Vol. 10 Iss: 3/4 pp. 77-83.

Cherrington, David J. 1995. The Management of Human Resources. Englewood Cliffs, NJ: Prentice-Hall.

Covey, Stephen R. 1989. The 7 Habits of Highly Effective People. United Kingdom: Simon \& Schuster.

Efferin, S. dan Soeherman, B. 2010. Seni Perang Sun Zi dan Sistem Pengendalian Manajemen: Filosofi dan Aplikasi (Sun Zi's the Art of War and Management Control System: Philosophy and Application). Jakarta, Indonesia: PT Elex Media Komputindo.

Faisal, Akbar. 2009. Komentar: Machiavelli, Pemasaran Politik dan Menemukan Kembali Pemerintahan. http://www.akbarfaizal.com/index.php?option=com_content\&view=article \&id=847:mereka-bicara-tentang-partaihanura\&catid=119:politik\&Itemid=101 (diunduh tanggal 11 November 2015).

Farneworth, Ellis. 2001. Art of War. Cambridge: Da Capo Press.

FightMediocrity. 2015. THE PRINCE BY NICCOLO MACHIAVELLI| ANIMATED BOOK REVIEW. https://www.youtube.com/watch?v=9SSV6mwPfTI (diunduh tanggal 16 Aguustus 2015).

History Today. 2014. Vincent Barnett reveals that there is more to Machiavelli than his notorious reputation. http://www.historytoday.com/vincentbarnett/niccolo-machiavelli-\%E2\%80\%93-cunning-critic-political-reason.

(diunduh tanggal 16 Oktober 2015).

Hongren, Charles, Garu Sundem, and William Stratton. 2005. Introduction to Management Accounting. USA: Pearson Prentice Hall.

Jansen M.C, dan William, H. M., 1976. Theory of the Firm: Managerial Behavior, Journal of Financial Economics, October, 1976, V. 3, No. 4, pp. 305-360.

Machiavelli, Niccolo. 1998. The Discources. London, England : Penguin Books. Machiavelli, Niccolo. 2001. The Prince. London, England : Penguin Books.

Mathis, Robert L dan Jackson John H. 2002. Human Resoursce Management, Alih Bahasa. Jakarta : Salemba Empat. 
Merchant, K. A and W.A. Van der Stede. 2003. Management Control System: Performance Measurement, Evaluation and Incentives. London, UK: Prentice Hall.

Moore, Simon. 2012. Ideals and Realities: Renaissance State Communication in Machiavelli's the Prince and More's Utopia. Public Relations Review, Vol. 38 Iss: 3 pp. 383-389.

Sciencebooth. 2013. Pengertian dan Komponen COSO Framework. http://sciencebooth.com/2013/05/21/pengertian-dan-komponen-cosoframework/ (diunduh tanggal 29 November 2015)

Setiawan, Ebta. 2015. Kamus Besar Bahasa Indonesia(Edisi III). Indonesia: Balai Pustaka.

Soeherman, Bonnie. 2015. Membangun Model Konseptual Sistem Pengendalian Manajemen Holistik Industri Kreatif Media Digital Berbasis Seni Perang Sun Zi dan Kitab Ramayana Walmiki: Studi pada Proyek The Adventures of Wanara PT. Mekanima Inspira Negara. Disertasi Doktor pada Universitas Airlangga: tidak diterbitkan.

The Independence. 2015. Exclusive: Tesco axes $P w C$ as auditor after accounting scandal. http://www.independent.co.uk/news/business/news/exclusivetesco-axes-pwc-as-auditor-after-accounting-scandal-10240260.html (diunduh tanggal 5 September 2015).

The School of Life. 2015. POLITICAL THEORY - Niccolò Machiavelli. https://www.youtube.com/watch?v=AOX10Ll_t9s (diunduh tanggal 15 Agustus 2015). 